\title{
Chronic obstructive pulmonary disease exacerbations and periodontitis: a possible association Hesham A. AbdelHalima ${ }^{\mathrm{a}}$, Heba H. AboEINaga ${ }^{\mathrm{b}}$, Reham L. Aggour ${ }^{\mathrm{c}}$
}

\begin{abstract}
Background There is an increasing interest concerning the potential link between both chronic obstructive pulmonary disease (COPD) and chronic periodontitis; therefore the association became the research focus.
\end{abstract}

Objective This study intended to evaluate the potential association between the frequency of COPD exacerbations and chronic periodontitis.

Patients and methods A total of 250 male patients with COPD were included in the study and were categorized into two groups according to the frequency of exacerbations per year: group 1 had patients with frequent exacerbations (having $\geq 2$ exacerbations in last year) and group 2 had patients with infrequent exacerbations (having $<2$ exacerbations in last year). They were compared regarding age, smoking history, education background, information of their oral hygiene behaviors, calculated modified Medical Research Council dyspnea scale, calculated COPD assessment test, the number of exacerbations and hospitalizations in the past year, prebronchodilator and postbronchodilator spirometry, calculated plaque index, bleeding index, probing pocket depth, clinical attachment level, and measured high-sensitivity C-reactive protein. Correlations between variables were examined. Logistic regression test was performed to explore the concurrent influences of periodontal health variables on the frequency of exacerbations.

\section{Introduction}

The possible relationship between both chronic obstructive pulmonary disease (COPD) and 'chronic periodontitis' has become an increasing focal point of research [1]. The mechanisms suggested to connect periodontitis and COPD include oral elements aspiration into the trachea-bronchial tree, overflow of generated inflammatory cells, and cell mediators into the circulation together with either oral cavity or lungderived blood circulating bacteria which stimulates an acute-phase reaction. Moreover, cytokines and other mediators or substances like oxygen-free radicals that may be released by polymorphs at distant sites also have an essential role [2].

The existing data back the hypothesis that periodontitis and COPD might be causally associated, increasing the likelihood that dealing one disorder can affect the other regarding its progression and severity. The resemblances in both processes (e.g. chronic neutrophilic inflammation, neutrophil dysfunction, and loss of connective tissue) propose a common pathophysiology and favor the suggestion of association [3].
Results This study evidenced that all periodontal health variables were significantly correlated with smoking status, modified Medical Research Council dyspnea scale, COPD assessment test, number of exacerbations and hospitalizations per year, and C-reactive protein level. Simplified oral hygiene index, plaque index, bleeding index, gingival index, probing pocket depth, and clinical attachment level were significantly correlated with most of the spirometry data.

Conclusion Periodontal health variables were considerably associated with the frequency of COPD exacerbations.

Egypt J Bronchol 2018 12:303-309

(C) 2018 Egyptian Journal of Bronchology

Egyptian Journal of Bronchology 2018 12:303-309

Keywords: chronic periodontitis, chronic obstructive pulmonary disease, exacerbations, oral hygiene

aRespiratory Medicine Department, Faculty of Medicine, Ain Shams University, Cairo, ${ }^{b}$ Respiratory Medicine Department, Faculty of Medicine, October 6 University, Giza, ${ }^{\circ}$ Oral Medicine and Periodontology Department, Faculty of Dentistry, October 6 University, Egypt

Correspondence to Hesham Atef AbdelHalim, MD, Respiratory Medicine Department, Ain Shams University, Cairo, Egypt. 8C, Opera City Compound, Sheikh Zayed, P.O.: 12563, Giza, Egypt. Tel: +202 38515201; fax: +201224474750 e-mail: heshamatef@med.asu.edu.eg

Received 16 February 2018 Accepted 19 March 2018

This was also proved in previous studies that evidenced an association of chronic periodontitis with additional chronic diseases such as chronic renal disease and renal dysfunction [4]; moreover, another study proved as well the association of COPD with concealed renal impairment [5].

Although the evidence of the association between them is becoming more solid, there is still a lack of conclusive research studies designed to verify their causal relationship, the degree of influence, and treatment effects. Building up of plaque permits the growth of bacteria, especially anaerobes, which lead to the polymorph recruitment through a series of mechanisms [1].

Repeated infective exacerbations in patients with COPD lead to increasing incidence of morbidity and enhanced

This is an open access journal, and articles are distributed under the terms of the Creative Commons Attribution-NonCommercial-ShareAlike 4.0 License, which allows others to remix, tweak, and build upon the work non-commercially, as long as appropriate credit is given and the new creations are licensed under the identical terms. 
mortality. The oral cavity is a main reservoir for the pathogenic respiratory organisms which are able to be aspirated into the lungs, thereby increasing the hazards of pulmonary infections [6]. Periodontal treatment can lessen the colonized pathogenic organisms on the teeth overlays and consequently may decrease the rate of COPD exacerbations [7].

The aim of the present study is to evaluate the influence of chronic periodontitis on exacerbation frequency in patients with COPD.

\section{Patients and methods}

The is a cross-sectional study that included 250 male patients having COPD, who were enrolled from the inpatient wards of pulmonary medicine of Ain Shams University Hospital and October 6 University Hospital in the period from 1 July 2017 to 1 January 2018. The diagnosis and combined assessments of all patients with COPD were performed clinically and functionally consistent with the Global Initiative for Obstructive Lung Disease 2017 criteria [8].

The inclusion criteria were patients with age of at least 30 years and possessing more than 10 teeth.

The exclusion criteria were exacerbations within the last month at the time of enrollment; patients having other chronic lung diseases, decompensated systemic diseases, and malignancies; patients receiving drugs that could affect periodontal state (e.g. phenytoin, tetracyclines, or cyclosporine); patients who underwent periodontal management less than 6 months before enrollment.

The next data were gathered from the participants: clinical histories with emphasis on age, smoking history, education background, and information of their oral hygiene behaviors, including (the use of dental floss, regular tooth brushing, routine visits to dentists in the preceding year), calculated modified Medical Research Council dyspnea scale (mMRC) and chronic obstructive pulmonary disease assessment test (CAT), exacerbations, and hospitalization frequency in the last year. Clinical examinations including anthropometric measures (height, weight, calculated BMI), chest radiography, prebronchodilator and postbronchodilator spirometry, and high-sensitivity C-reactive protein (CRP) were also performed. Periodontal variables including plaque index (PI), gingival index (GI), bleeding upon probing, bleeding index (BI), clinical attachment level (CAL), and probing pocket depth (PPD) were measured.
All patients were classified according to the frequency of exacerbations in the last year into two groups: group 1 included patients with frequent exacerbations (exacerbations $\geq 2$ in the last year) and group 2 included patients with infrequent exacerbations (exacerbations $<2$ in the last year).

All participants gave a written consent. The research was accepted by the review panel of the Chest Department of Ain Shams University.

\section{Spirometry}

The spirometry examinations were done in the Chest Department of Ain Shams University by means of Spirometrics ENC Flowmate machine (Spring Valley, New York, USA) and in October 6 University with Spirobank GUSB, class II machine (MIR SRL, S/N 806734; Rome, Italy). The assessments were done before and after $20 \mathrm{~min}$ of receiving an inhaled $\beta 2$ agonist (salbutamol $5 \mathrm{mg} / \mathrm{ml}$ in $9 \%$ saline solution), dispensed through a nebulizer. The prebronchodilator and postbronchodilator spirometry results were assessed in all participants following the ATS/ERS criteria [9].

\section{Periodontal examination}

Periodontal variables of all patients were assessed clinically. Periodontal examination was performed on all existing teeth (excluding the third molar teeth). Periodontal assessment involved the following parameters: (a) Simplified Oral Hygiene Index [10]; (b) PI, which was recorded on a scale of $0-3$ for each tooth after drying out with the air [11]; (c) bleeding upon probing, judged as absent or present; (d) BI on a scale of $0-5$, when any bleeding was noticed [12]; (e) GI [13]; and (f) PPD and CAL. PPD was recorded in millimeters. The recession was estimated to be positive when the free gingival edge appeared apically situated to the cemento-enamel junction, and negative if it occurred in a coronal position to cemento-enamel junction. Calculations of CAL were done by summation of PPD and recession value [14]; the severity of periodontal affection was classified by categorizing PPD into mild more than 3 and less than $5 \mathrm{~mm}$, moderate of at least 5 and less than $7 \mathrm{~mm}$, and severe of at least $7 \mathrm{~mm}$ and CAL into mild $1-2 \mathrm{~mm}$, moderate $3-4 \mathrm{~mm}$, and severe of at least $5 \mathrm{~mm}$. PPD and CAL were documented at six spots for each tooth (disto-buccal, buccal, mesio-buccal, disto-lingual, lingual, and mesio-lingual sites), whereas PI and bleeding upon probing were documented at four spots for each tooth (disto-buccal, buccal, mesio-buccal, and lingual sites) [15]. The clinical assessment was achieved using the manual calibrated periodontal probe (DB775R; Aesculap, Tuttilige, Germany). Measurements were approximated to the closest millimeter. 
The periodontal clinical assessments were performed by two qualified dentists who were blind to the patient's status. For standardization, they measured PPD and CAL in 10 patients. The inter-examiner reproducibility was significant; $\kappa$ values were all above 0.8 $(P<0.001)$ for the variables analyzed by both examiners and within self-comparison of each individual dentist.

Chronic periodontitis was diagnosed according to the American Academy of Periodontology task force report on the update to the 1999 classification of periodontal diseases and conditions [15].

\section{Data analysis}

Comparisons between data variables were done using independent-sample $t$-tests for quantitative variables and $\chi^{2}$-test for categorical variables. Simple correlations between variables were tested using the Pearson's product correlation coefficient. Logistic regression test was performed to explore the concurrent influences of periodontal variables on the frequency of exacerbations. Statistical analyses were done using the statistical package for the social sciences (SPSS version 17; SPSS Inc., Chicago, Illinois, USA) statistical software. Significance was considered at $P$ value less than 0.05 .

\section{Results}

Two hundred and fifty male patients with COPD completed the study. The patients were categorized into two groups. Group 1 included 134 patients who were frequent exacerbators and had a mean age of $56.75 \pm 10.42$ years, and group 2 included 116 patients who were infrequent exacerbators and had a mean age of $55.28 \pm 9.12$ years.

The characteristic information of participants and comparisons between the two groups showed insignificant differences regarding age and BMI. There were significant differences regarding smoking, being more in the frequent exacerbation group $(P=0.03)$, whereas patients of both groups were equally distributed regarding the smoking status. The frequent exacerbation group of patients had a lower level of education (58.2\%) than the infrequent exacerbation group $(54.3 \%) \quad(P=0.04)$. The frequent exacerbator group patients were more in the categories $\mathrm{C}$ and $\mathrm{D}$, whereas patients in group 2 were more likely to belong to categories $\mathrm{A}$ and $\mathrm{B}$.

There were significant statistical dissimilarities between both groups regarding mMRC $(P=0.04)$, CAT, hospitalizations per year, all spirometry parameters, and $\mathrm{CRP}$, being worse in the group $1(P<0.001)$
(Table 1). Periodontal health variables within patients of frequent exacerbation and infrequent exacerbation COPD groups are significantly different regarding simplified oral hygiene index (OHI-S) $(P<0.001)$.

PI up to $2 \mathrm{~mm}$ was more frequent in group 2 (the infrequent exacerbation group), whereas group 1 (the frequent exacerbation group) more frequently had PI more than $2 \mathrm{~mm}(P=0.029)$.

Group 1 more frequently had BI more than 2.5 , whereas group 2 more frequently had BI up to $2.5(P=0.042)$.

Group 1 more frequently had moderate to severe PPD $(P<0.001)$ whereas group 2 more frequently had mild PPD.

Table 1 Data description and comparisons between both groups concerning anthropometric, clinical, spirometry, and laboratory data

\begin{tabular}{|c|c|c|c|}
\hline & $\begin{array}{c}\text { Frequent } \\
\text { exacerbators } \\
(n=134)\end{array}$ & $\begin{array}{c}\text { Infrequent } \\
\text { exacerbators } \\
(n=116)\end{array}$ & $P^{\dagger}$ \\
\hline Age (years) & $56.75 \pm 10.42$ & $55.28 \pm 9.12$ & 0.24 \\
\hline BMI $\left(\mathrm{kg} / \mathrm{m}^{2}\right)$ & $25.39 \pm 5.98$ & $26.36 \pm 6.69$ & 0.23 \\
\hline $\begin{array}{l}\text { Smoking } \\
\text { (pack years) }\end{array}$ & $36.51 \pm 18.95$ & $30.34 \pm 26.12$ & $0.03^{*}$ \\
\hline \multicolumn{4}{|l|}{ Smoking status } \\
\hline Current smoker & $102(76.1)$ & $93(80.2)$ & 0.515 \\
\hline Ex-smoker & $30(22.4)$ & $20(17.2)$ & \\
\hline Nonsmoker & $2(1.5)$ & $3(2.6)$ & \\
\hline \multicolumn{4}{|l|}{ Level of education } \\
\hline $\begin{array}{c}\text { Higher } \\
\text { education }\end{array}$ & $56(41.8)$ & $53(45.7)$ & $0.04^{*}$ \\
\hline $\begin{array}{c}\text { Lower } \\
\text { education }\end{array}$ & $78(58.2)$ & $63(54.3)$ & \\
\hline MRC & $3.13 \pm 1.33$ & $2.78 \pm 1.42$ & $0.04^{*}$ \\
\hline CAT & $22.51 \pm 8.56$ & $17.28 \pm 7.31$ & $<0.001^{\star}$ \\
\hline $\begin{array}{l}\text { Hospitalizations } \\
\text { (N/year) }\end{array}$ & $2.06 \pm 1.72$ & $0.93 \pm 1.05$ & $<0.001^{*}$ \\
\hline \multicolumn{4}{|l|}{ COPD categories } \\
\hline$A$ and $B$ & $4(3)$ & $67(57.8)$ & $<0.001^{\star}$ \\
\hline$C$ and $D$ & $130(97)$ & $49(42.2)$ & \\
\hline $\begin{array}{l}\text { FVC } \\
\text { (\% predicted) }\end{array}$ & $57.83 \pm 21.56$ & $69.84 \pm 25.74$ & $<0.001^{*}$ \\
\hline $\begin{array}{l}\mathrm{FEV}_{1} \\
\text { (\% predicted) }\end{array}$ & $50.08 \pm 22.70$ & $62.56 \pm 21.21$ & $<0.001^{\star}$ \\
\hline $\begin{array}{l}\mathrm{FEV}_{1} / \mathrm{FVC} \\
(\% \text { predicted })\end{array}$ & $59.86 \pm 8.93$ & $62.47 \pm 8.12$ & $0.02^{*}$ \\
\hline $\begin{array}{l}\text { MMEF } \\
\text { (\% predicted) }\end{array}$ & $37.48 \pm 26.99$ & $44.20 \pm 17.22$ & $0.02^{*}$ \\
\hline $\begin{array}{l}\text { PEF } \\
\text { (\% predicted) }\end{array}$ & $42.51 \pm 20.16$ & $57.62 \pm 17.53$ & $<0.001^{\star}$ \\
\hline CRP (mg/dl) & $3.77 \pm 3.00$ & $2.52 \pm 2.66$ & $<0.001^{\star}$ \\
\hline
\end{tabular}

Data are presented as mean \pm SD for quantitative data or frequency (\%) for categorical data. CAT, chronic obstructive pulmonary disease assessment test; CRP, C-reactive protein; MMEF, maximum mid-expiratory flow; MRC, Medical Research Council; PEF, peak expiratory flow. ${ }^{*} P<0.05$, statistically significant. ${ }^{\dagger} P$-value acquired from independent samples $t$-test for quantitative variables and $\chi^{2}$-test for categorical variables. 
CAL was moderate to severe in the frequent exacerbators $(P<0.001)$ but mild in the infrequent exacerbation group (Table 2).

There were statistically significant correlations between the age of participants and all periodontal health variables $(P<0.05)$ except OHI-S. BMI correlated significantly with BI and CAL $(P<0.001$ and $<0.05$, respectively). All periodontal health variables were significantly correlated with smoking status,

Table 2 Data description and comparisons between the two groups regarding periodontal health variables

\begin{tabular}{|c|c|c|c|}
\hline & $\begin{array}{c}\text { Frequent } \\
\text { exacerbators } \\
(n=134)\end{array}$ & $\begin{array}{l}\text { Infrequent } \\
\text { exacerbators } \\
(n=116)\end{array}$ & $P^{\dagger}$ \\
\hline OHI-S & $2.84(1.20)$ & $1.50(0.87)$ & $<0.001^{*}$ \\
\hline \multicolumn{4}{|l|}{$\mathrm{PI}(\mathrm{mm})$} \\
\hline$\leq 2$ & $60(44.8)$ & 68 (58.6) & \multirow[t]{2}{*}{$0.029^{*}$} \\
\hline$>2$ & $74(55.2)$ & $48(41.4)$ & \\
\hline GI & $1.57(0.98)$ & $0.36(0.52)$ & $<0.001^{*}$ \\
\hline \multicolumn{4}{|l|}{$\mathrm{BI}$} \\
\hline$\leq 2.5$ & $59(44)$ & $66(56.9)$ & \multirow[t]{2}{*}{$0.042^{*}$} \\
\hline$>2.5$ & $75(56)$ & $50(43.1)$ & \\
\hline \multicolumn{4}{|l|}{$P P D^{a}$} \\
\hline Mild & $12(9)$ & $86(74.1)$ & \multirow[t]{3}{*}{$<0.001^{*}$} \\
\hline Moderate & $43(32)$ & $26(22.4)$ & \\
\hline Severe & 79 (59) & $4(3.5)$ & \\
\hline \multicolumn{4}{|l|}{$\mathrm{CAL}^{\mathrm{b}}$} \\
\hline Mild & $14(10.4)$ & $90(77.6)$ & \multirow[t]{3}{*}{$<0.001^{*}$} \\
\hline Moderate & $36(26.9)$ & $21(18.1)$ & \\
\hline Severe & $84(62.7)$ & $5(4.3)$ & \\
\hline
\end{tabular}

Data are presented as mean \pm SD for quantitative data or frequency (\%) for categorical data. BI, bleeding index; CAL, clinical attachment level; Gl, gingival index; OHI-S, simplified oral hygiene index; PI, plaque index; PPD, probing pocket depth. ${ }^{\text {a Mild }}$ (3-4 mm), moderate $(5-7 \mathrm{~mm})$, severe $(\geq 7 \mathrm{~mm}) .{ }^{b}$ Mild $(1-2 \mathrm{~mm})$, moderate $(3-4 \mathrm{~mm})$, severe $(\geq 5 \mathrm{~mm})$. ${ }^{*} P<0.05$, statistically significant. ${ }^{\dagger} P$-value acquired from independent samples $t$-test for quantitative variables and $\chi^{2}$-test for categorical variables. modified MRC dyspnea scale, CAT, the frequency of exacerbations and hospitalizations in last year, and CRP level. Regarding spirometry data, OHI-S, PI, BI, and GI were significantly correlated with all spirometry data, whereas PPD and CAL were significantly correlated with all spirometry data except forced expiratory volume in one second $\left(\mathrm{FEV}_{1}\right)$ /forced vital capacity (FVC) ratio (Table 3$)$.

Logistic regression test was done to predict the influence of periodontal health variables on the frequency of exacerbation (Table 4).

Overall, $71.9 \%$ of the frequent exacerbations are explained by the logistic regression model (the overall accuracy of this model is $86.8 \%$ with a predicted probability of 0.5 or greater). GI appeared to be the most important predictor for frequent exacerbations [odds ratio $(\mathrm{OR})=5.47,95 \%$ confidence interval $(\mathrm{CI})$ : 2.54-11.78, $P<0.001$ ] followed by PI more than $2 \mathrm{~mm}$ (OR=2.68, 95\% CI: 0.99-7.20, $P=0.05)$.

When the periodontal health variables were combined with the demographic, clinical, CRP level and spirometry data, a new logistic regression model was created (Table 5).

Overall, $92.5 \%$ of the frequent exacerbations are explained by this model, with an overall accuracy of $95.2 \%$ (with a predicted probability $\geq 0.5$ ). GI did not remain a significant predictor of frequent exacerbations, whereas PI more than $2 \mathrm{~mm}$ $(\mathrm{OR}=0.014,95 \% \mathrm{CI}: 0.001-0.23)$ and BI more than $2.5(\mathrm{OR}=0.596,95 \% \mathrm{CI}: 0.36-0.98)$ was significantly associated with frequent exacerbations $(P=0.003$ and 0.04 , respectively). PI and $\mathrm{BI}$ in the last regression

Table 3 Correlations between oral indices and patients' demographic, clinical, and spirometry data

\begin{tabular}{|c|c|c|c|c|c|c|}
\hline & \multicolumn{6}{|c|}{$P^{\dagger}$} \\
\hline & OHI-S & $\mathrm{Pl}$ & $\mathrm{BI}$ & GI & PPD & CAL \\
\hline Age (years) & 0.135 & $0.003^{*}$ & $0.037^{\star}$ & $0.008^{*}$ & $0.016^{*}$ & $0.039^{*}$ \\
\hline BMI $\left(\mathrm{kg} / \mathrm{m}^{2}\right)$ & 0.848 & 0.521 & $<0.001^{*}$ & 0.129 & 0.119 & $0.012^{*}$ \\
\hline Smoking (pack years) & $<0.001^{*}$ & $<0.001^{*}$ & $<0.001^{*}$ & $<0.001^{*}$ & $<0.001^{*}$ & $<0.001^{*}$ \\
\hline MRC & $<0.001^{*}$ & $<0.001^{*}$ & $<0.001^{*}$ & $<0.001^{*}$ & $0.014^{*}$ & $0.004^{*}$ \\
\hline CAT & $<0.001^{*}$ & $<0.001^{*}$ & $<0.001^{*}$ & $<0.001^{*}$ & $<0.001^{*}$ & $<0.001^{*}$ \\
\hline Exacerbations (N/year) & $<0.001^{\star}$ & $<0.001^{\star}$ & $<0.001^{*}$ & $<0.001^{*}$ & $<0.001^{\star}$ & $<0.001^{*}$ \\
\hline Hospitalizations (N/year) & $<0.001^{*}$ & $<0.001^{*}$ & $<0.001^{*}$ & $<0.001^{*}$ & $<0.001^{*}$ & $<0.001^{*}$ \\
\hline FVC (\% predicted) & $<0.001^{\star}$ & $<0.001^{*}$ & $<0.001^{\star}$ & $<0.001^{*}$ & $<0.001^{*}$ & $<0.001^{*}$ \\
\hline $\mathrm{FEV}_{1}(\%$ predicted) & $<0.001^{*}$ & $<0.001^{*}$ & $<0.001^{*}$ & $<0.001^{\star}$ & $<0.001^{\star}$ & $<0.001^{*}$ \\
\hline $\mathrm{FEV}_{1} / \mathrm{FVC}(\%$ predicted) & $0.001^{*}$ & $<0.001^{*}$ & $<0.001^{*}$ & $<0.001^{*}$ & 0.142 & 0.053 \\
\hline MMEF (\% predicted) & $0.002^{*}$ & $<0.001^{*}$ & $<0.001^{*}$ & $<0.001^{*}$ & $0.027^{*}$ & $0.002^{*}$ \\
\hline PEF (\% predicted) & $<0.001^{*}$ & $<0.001^{\star}$ & $<0.001^{\star}$ & $<0.001^{\star}$ & $<0.001^{\star}$ & $<0.001^{*}$ \\
\hline CRP (mg/dl) & $0.001^{*}$ & $<0.001^{\star}$ & $<0.001^{*}$ & $<0.001^{\star}$ & $0.002^{*}$ & $<0.001^{*}$ \\
\hline
\end{tabular}

$\mathrm{BI}$, bleeding index; CAL, clinical attachment level; CAT, chronic obstructive pulmonary disease assessment test; CRP, C-reactive protein; GI, gingival index; MMEF, maximum mid-expiratory flow; MRC, Medical Research Council; OHI-S, simplified oral hygiene index; PI, plaque index; PPD, probing pocket depth. ${ }^{\star} P<0.05$, statistically significant. ${ }^{\dagger} P$-value acquired from Pearson product of correlation coefficient. 
Table 4 Logistic regression for frequency of exacerbations concerning patients' periodontal health variables

\begin{tabular}{lcc}
\hline & OR $(95 \% \mathrm{Cl})$ & $P$ \\
\hline OHI-S & $1.16(0.64-2.1)$ & 0.62 \\
$\mathrm{PI}>2 \mathrm{~mm}$ & $2.68(0.99-7.20)$ & 0.05 \\
$\mathrm{GI}$ & $5.47(2.54-11.78)$ & $<0.001^{*}$ \\
$\mathrm{BI}>2.5$ & $1.36(0.56-3.41)$ & 0.49 \\
$\mathrm{PPD}(\mathrm{mm})^{\mathrm{a}}$ & & \\
$\quad$ Moderate & $0.07(0.003-1.65)$ & 0.10 \\
$\quad$ Severe & $0.24(0.02-3.42)$ & 0.30 \\
CAL (mm) & & \\
$\quad$ Moderate & $0.21(0.01-3.84)$ & 0.29 \\
$\quad$ Severe & $0.55(0.05-6.59)$ & 0.64 \\
\hline
\end{tabular}

Data are presented as odds ratio $(95 \% \mathrm{Cl})$. BI, bleeding index; $\mathrm{CAL}$, clinical attachment level; $\mathrm{Cl}$, confidence interval; GI, gingival index; OHI-S, simplified oral hygiene index; OR, odds ratio; PI, plaque index; PPD, probing pocket depth. ${ }^{*} P<0.05$, statistically significant. ${ }^{a}$ Mild $(3-4 \mathrm{~mm})$, moderate $(5-7 \mathrm{~mm})$, severe $(\geq 7 \mathrm{~mm})$. Mild (1-2 mm), Moderate (3-4 mm), severe $(\geq 5 \mathrm{~mm})$.

Table 5 Logistic regression for frequency of exacerbations concerning patients' periodontal health variables, after adding demographic, clinical, and spirometry data

\begin{tabular}{llc}
\hline & \multicolumn{1}{c}{ OR $(95 \% \mathrm{Cl})$} & $P$ \\
\hline Age (years) & $0.73(0.60-0.87)$ & $0.001^{*}$ \\
BMI (kg/m²) & $1.48(1.08-2.03)$ & $0.014^{*}$ \\
Smoking (pack years) & $3.25(1.73-6.13)$ & $<0.001^{*}$ \\
Current smokers & $2.75(0.28-26.91)$ & 0.38 \\
Low level of education & $0.20(0.05-0.82)$ & $0.025^{*}$ \\
MRC & $0.30(0.11-0.88)$ & $0.029^{*}$ \\
CAT & $1.06(0.86-1.29)$ & 0.60 \\
Hospitalizations (N/year) & $1.29(0.30-5.57)$ & 0.73 \\
COPD category C-D & $0.002(0.00-0.06)$ & $<0.001^{*}$ \\
FVC (\% predicted) & $1.11(1.0-1.24)$ & 0.051 \\
FEV $1 \%$ predicted) & $0.95(0.79-1.13)$ & 0.54 \\
FEV 1 /FVC (\% predicted) & $1.02(0.89-1.17)$ & 0.81 \\
MMEF (\% predicted) & $1.11(1.03-1.20)$ & $0.01^{*}$ \\
PEF (\% predicted) & $0.76(0.64-0.90)$ & $0.002^{*}$ \\
CRP (mg/dl) & $1.0(0.61-1.63)$ & 0.995 \\
OHI-S & $0.19(0.02-1.48)$ & 0.11 \\
PI >2 mm & $0.014(0.001-0.23)$ & $0.003^{*}$ \\
GI & $3.82(0.44-33.39)$ & 0.23 \\
BI >2.5 & $0.596(0.36-0.98)$ & $0.04^{*}$ \\
PPD (mm) & & \\
Moderate & & 0.62 \\
Severe & $0.166(0.000-215.17)$ & 0.54 \\
CAL (mm) & & \\
Moderate & $0.23(0.002-24.44)$ & 0.097 \\
Severe & $0.003(0.000-2.86)$ & 0.73 \\
\hline
\end{tabular}

Data are presented as odds ratio $(95 \% \mathrm{Cl})$. BI, bleeding index; CAL, clinical attachment level; CAT, chronic obstructive pulmonary disease assessment test; $\mathrm{Cl}$, confidence interval; COPD, chronic obstructive pulmonary disease; CRP, C-reactive protein; OHI-S, simplified oral hygiene index; MMEF, maximum mid-expiratory flow; MRC, Medical Research Council; PEF, peak expiratory flow; $\mathrm{PI}$, plaque index; PPD, probing pocket depth. ${ }^{\mathrm{a}}$ Mild $(3-4 \mathrm{~mm})$, moderate $(5-7 \mathrm{~mm})$, severe $(\geq 7 \mathrm{~mm})$. ${ }^{\mathrm{b}}$ Mild $(1-2 \mathrm{~mm})$, moderate (3-4 mm), severe $(\geq 5 \mathrm{~mm})$. ${ }^{*} P<0.05$, statistically significant.

model came after smoking to be considered the most significant predictors for frequent exacerbations $(P<0.001)$ (whereas, the existing smoking status was not a significant predictor), higher BMI $(P=0.014)$, increasing age $(P=0.001)$, lower education level $(P=0.025)$, higher modified MRC score $(P=0.029)$, COPD categories $\mathrm{C}$ and $\mathrm{D}(P<0.001)$, and lower maximum mid-expiratory flow and peak expiratory flow percent predicted values $(P=0.01$ and 0.002 , respectively).

\section{Discussion}

There are many previous observational studies that have evidenced a clinical association between periodontitis and COPD, proving that populations with the periodontal illness had an overall increased risk for developing COPD, but the mechanisms remain debatable [16].

To our paramount knowledge, it was found that various strategies had been tried for limiting the deteriorating symptoms due to COPD, including pacing activities to conserve energy, adapting activities to breathlessness, and smoking cessation. However, a limited number of the strategies mentioned included oral hygiene measures [17].

Unfortunately, the data provided by previous researches that have evaluated the associations between COPD and periodontitis remain controversial [18-22] owing to the rarity of the uniformly accepted definition and how the diagnosis was established for both COPD and periodontitis. However, this study provided an optimum assessment of COPD and periodontitis according to the latest international guidelines for both $[8,15]$.

It was proved that the yearly number of hospital admissions and emergency room visits concerning the patients having COPD increased proportionately with the existence of periodontitis [23].

This study evidenced that all periodontal health variables were positively correlated with smoking, CRP level, modified MRC dyspnea score, and CAT.

There were significant differences regarding smoking, being more in the frequent exacerbation group; besides, patients in the frequent exacerbation group had a lower level of education than those in the infrequent exacerbation group. These results support those of Chung et al. [19] and others who also recorded that patients with COPD were more illiterate and belonged to a lesser income group [24]. Moreover, Holtfreter et al. [25] realized that patients with greater periodontal indices had lower education level, were 
more frequently current smokers, had worse spirometry data, and had more intensities of systemic inflammation. On the contrary, Bhavsar et al. [18] did not observe any discrepancies in the socioeconomic class or the educational levels among their COPD group and control group.

Smoking appeared associated significantly with the frequent exacerbation group and all periodontal health variables. This is owing to the action of tobacco, which slows the healing process by causing deeper pockets [26]. For this reason, another study discovered that smoking instead of COPD was the main hazard factor for periodontitis [21].

The existing smoking status does not prove to be significantly associated with the frequency of COPD exacerbation.

Regarding spirometry data, OHI-S, PI, BI, GI, PPD, and CAL were significantly correlated with almost all the spirometry data; accordingly, the results pointed to the significant statistical connection between the decline of spirometry data and the severity degree of periodontitis. This agrees with the few studies that have investigated the relationship between periodontitis and respiratory functions [25]. Moreover, the results of this study evidenced that all periodontal health variables including PI more than $2 \mathrm{~mm}$, BI more than 2.5, PPD, and CAL are significantly higher in the frequently exacerbating group. Moreover, it is significantly correlated with the frequency of hospitalizations in the previous year. This agrees with another study which concluded that a higher score for dental plaque and low tooth brushing frequency are significantly correlated with COPD exacerbations [18].

There is proven evidence that high score of PI and high OHI-S are significantly correlated with COPD exacerbations. It was proved that dental plaque represents a reservoir for lung pathogens, as they colonize the subgingival areas and shed into the saliva [27]. Besides, other investigations also stated the connections between dental plaque and oral hygiene with COPD exacerbations [27], pneumonia [28] and ventilator-associated pneumonia $[29,30]$.

Although the current study did not involve a bacteriological investigation, which may be a limiting issue, as perhaps it was thought that they were not technique sensitive, it included another biological marker, CRP, which is also elevated in the frequently exacerbating COPD group rather than in nonexacerbators. Adding to this is the positive correlation of CRP with all periodontal health variables, which supports confirmation of current systemic inflammation.As this study proved that periodontal health variables were worse in patients with frequent COPD exacerbation than infrequent exacerbation, it is deduced that better oral hygiene and frequent expert oral health care may be a potential protective measure against COPD exacerbations as it was applied previously in another study [31]. Additionally, although dental plaque is the major cause of the aggravation of periodontal disorders, the successful removal of dental plaque is fundamental for avoiding periodontitis and may enhance lung function, decrease the incidence of COPD exacerbation, and improve quality of life [32].

The influence of periodontal health variables on the frequency of exacerbation was examined in this study using a logistic regression analysis in which GI showed to be the most important predictor, followed by PI. Moreover, after adjusting for other confounders, PI remained significantly associated with frequent exacerbation of patients with COPD in addition to $\mathrm{BI}$, which agrees with the results of a previous study [26].

\section{Conclusion}

This study revealed that periodontal health variables were significantly linked to COPD frequent exacerbations, and this may call attention toward enhancing oral hygiene and periodontal condition for a potential protective strategy against COPD exacerbations, which may decelerate the decline of patients' pulmonary functions.

\section{Financial support and sponsorship} Nil.

\section{Conflicts of interest}

There are no conflicts of interest.

\section{References}

1 Listgarten MA. Pathogenesis of periodontitis. J Clin Periodontol 1986; 13:418-425.

2 Sapey E, Bayley D, Ahmad A, Newbold P, Snell N, Stockley RA. Interrelationships between inflammatory markers in patients with stable COPD with bronchitis: intra-patient and inter-patient variability. Thorax 2008; 63:493-499.

3 Hobbins S, Chapple ILC, Sapey E, Stockley RA. Is periodontitis a comorbidity of COPD or can associations be explained by shared risk factors/behaviors?. Int J Chron Obstruct Pulmon Dis 2017; 12:1339-1349. 
4 Brito F, Almeida S, Cms F, Bregman R, Jhr S, Rg F. Extent and severity of chronic periodontitis in chronic kidney disease patients. J Periodontal Res 2012; 47:426-430.

5 AbdelHalim HA, AboEINaga HH. Is renal impairment an anticipated COPD comorbidity? Respir Care 2016; 61:1201-1206.

6 Shen TC, Chang PY, Lin CL, Wei CC, Tu CY, Hsia TC, et al. Impact of periodontal treatment on hospitalization for adverse respiratory events in asthmatic adults: a propensity-matched cohort study. Eur J Intern Med 2017; 46:56-60.

7 Zhou X, Wang Z, Song Y, Zhang J, Wang C. Periodontal health and quality of life in patients with chronic obstructive pulmonary disease. Respir Med $2011 ; 105: 67-73$

8 GOLD. Global srategy for the diagnosis, management, and prevention of chronic obstructive pulmonary disease. Glob Initiat Chronic Obstr Lung Dis 2015; 117:22-42.

9 Miller MR, Hankinson J, Brusasco V, Burgos F, Casaburi R, Coates A, et al. ATS/ERS Task Force: ATS/ERS standardisation of spirometry. Eur Respir J 2005; 26:319-338.

10 Greene JG, Vermillion JR. The simplified oral hygiene index. J Am Dent Assoc 1964; 68:7-13.

11 Silness J, Loe H, Silness J, Loe H. Periodontal disease in pregnancy. II. Correlation between oral hygiene and periodontal condtion. Acta Odontol Scand 1964; 22:121-135.

12 Mazza JE, Newman MG, Sims TN. Clinical and antimicrobial effect of stannous fluoride on periodontitis. J Clin Periodontol 1981; 8:203-212.

13 Löe $\mathrm{H}$. The gingival index, the plaque index and the retention index systems. J Periodontol 1967; 38:610-616.

14 Ramfjord SP. The periodontal disease index (PDI). J Periodontol 1967; 38:602-610

15 [No authors listed]. American Academy of Periodontology Task Force Report on the Update to the 1999 Classification of Periodontal Diseases and Conditions. J Periodontol 2015; 86:835-838.

16 Zeng XT, Tu ML, Liu DY, Zheng D, Zhang J, Leng W. Periodontal disease and risk of chronic obstructive pulmonary disease: a meta-analysis of observational studies. PLOS One 2012; 7:e46508.

17 Zhou X, Han J, Liu Z, Song Y, Wang Z, Sun Z. Effects of periodontal treatment on lung function and exacerbation frequency in patients with chronic obstructive pulmonary disease and chronic periodontitis: a 2-year pilot randomized controlled trial. J Clin Periodontol 2014; 41:564-572.

18 Bhavsar NV, Dave BD, Brahmbhatt NA, Parekh R. Periodontal status and oral health behavior in hospitalized patients with chronic obstructive pulmonary disease. J Nat Sci Biol Med 2015; 6:S93-S97.

19 Chung JH, Hwang HJ, Kim SH, Kim TH. Associations between periodontitis and chronic obstructive pulmonary disease: The 2010 to
2012 Korean National Health and Nutrition Examination Survey. $J$ Periodontol 2016; 87:864-871.

20 Peter KP, Mute BR, Doiphode SS, Bardapurkar SJ, Borkar MS, Raje DV Association between periodontal disease and chronic obstructive pulmonary disease: a reality or just a dogma? J Periodontol 2013; 84: 1717-1723.

21 Bergström J, Cederlund K, Dahlén B, Lantz AS, Skedinger M, Palmberg L, et al. Dental health in smokers with and without COPD. PLoS One 2013; 8 : e59492.

22 Barros SP, Suruki R, Loewy ZG, Beck JD, Offenbacher S. A cohort study of the impact of tooth loss and periodontal disease on respiratory events among COPD subjects: modulatory role of systemic biomarkers of inflammation. PLoS One 2013; 8:e68592.

23 Shen TC, Chang PY, Lin CL, Chen CH, Tu CY, Hsia TC, et al. Risk of periodontal diseases in patients with chronic obstructive pulmonary disease: a nationwide population-based cohort study. Medicine (Baltimore) 2015; 94:e2047.

24 Prasanna SJ. Causal relationship between periodontitis and chronic obstructive pulmonary disease. J Indian Soc Periodontol 2011; 15 359-365.

25 Holtfreter B, Richter S, Kocher T, Dörr M, Völzke H, Ittermann T, et al. Periodontitis is related to lung volumes and airflow limitation: a crosssectional study. Eur Respir J 2013; 42:1524-1535.

26 Liu Z, Zhang W, Zhang J, Zhou X, Zhang L, Song Y, et al. Oral hygiene, periodontal health and chronic obstructive pulmonary disease exacerbations. J Clin Periodontol 2012; 39:45-52.

27 Scannapieco FA. Role of oral bacteria in respiratory infection. $J$ Periodontol 1999; 70:793-802.

28 Fourrier F, Duvivier B, Boutigny H, Roussel-Delvallez M, Chopin C. Colonization of dental plaque: a source of nosocomial infections in intensive care unit patients. Crit Care Med 1998; 26:301-308.

29 Labeau SO, van de Vyver K, Brusselaers N, Vogelaers D, Blot SI. Prevention of ventilator-associated pneumonia with oral antiseptics: a systematic review and meta-analysis. Lancet Infect Dis 2011; 11:845-854.

30 Chan EY, Ruest A, Meade MO, Cook DJ. Oral decontamination for prevention of pneumonia in mechanically ventilated adults: systematic review and meta-analysis. Br Med J 2007; 334:889-893.

31 Apps LD, Harrison SL, Williams JEA, Hudson N, Steiner M, Morgan $M D$, et al. How do informal self-care strategies evolve among patients with chronic obstructive pulmonary disease managed in primary care? a qualitative study. Int J Chron Obstruct Pulmon Dis 2014 9:257-263.

32 Marsh PD, Head DA, Devine DA. Dental plaque as a biofilm and a microbial community - implications for treatment. J Oral Biosci 2015; 57:185-191. 